\title{
Enzymes: Their Activity and Role in Metabolism
}

\author{
Neerja Kapoor* \\ Department of Zoology, India \\ *Corresponding author: Neerja Kapoor, Department of Zoology, CMP College, Allahabad, India
}

\begin{tabular}{|c|c|}
\hline ARTICLE INFO & ABSTRACT \\
\hline Received: 幽 January 08, 2020 & Citation: Neerja Kapoor. Enzymes: Their Activity and Role in Metabolism. Biomed J Sci \\
\hline Published: 㓞 January 21, 2020 & \& Tech Res 24(4)-2020. BJSTR. MS.ID.004090. \\
\hline
\end{tabular}

\section{Introduction}

The cell protoplasm contains one thousand or more proteins, each bringing about one of the many chemical changers required for the maintenance of life. These proteins are called enzymes. Enzymes are soluble and colloidal organic catalysts which are synthesized in the body cell. The word enzyme was first introduced by Khune in 1878 and is derived from the original Greek word 'enzyme', which means "in-yeast". The word enzyme was given on speculation that the yeast cells role in fermentation was in reality due to a protein present within the cell and acting there as a catalyst. "An enzyme may be defined as a complex biological catalyst that is produced by a living organism in its cells to regulate the various physiological processes of the body". It is believed that for every enzyme in the living cell, there is a separate gene responsible for that enzyme's synthesis. As genes are self-duplicating units which remain unchanged in composition as they are passed on from one generation to another, there will be no change in enzyme and so the metabolism, behaviour and physical characteristics of a given species remain the same for generations. Only when there is a loss or change in one or more genes, there will be a change in the enzymes produced by these genes.

\section{Chemical Nature}

Many enzymes have been obtained in a highly purified form, and, indeed, may have been isolated as crystals. Since all of these crystalline enzymes have been proved to be protein, it is generally accepted that all enzymes are protein in nature. They are water soluble and most of them are colourless, but some are brown, red or green etc. All are insoluble in alcohol and most of them are destroyed or denatured by heat and a variety of chemical agents. Enzymes vary widely in molecular weight. Simple globular enzymes have molecular weights as low as 20,000 while conjugated globular enzymes may have molecular weights of several million. Enzymes are colloidal in nature and behave like colloids with a precipitation agent. The substance upon which the enzymes work is known as substrate.

\section{Terminology and Classification of Enzymes}

Enzymes may be conveniently classified into several major groups according to the chemical reactions which they catalyse. An International Commission in 1961, drafted specific rules for the classification and naming of enzymes. The Commission has proposed six main classes based on the type of reaction catalysed, with further subdivision on the basis of nature of reaction catalysed and the type of bond formed. The six main classes suggested by "International Union of Biochemists" are:

1. Oxidoreductases

2. Transferases

3. Hydrolases

4. Lyases

5. Isomerases

6. Ligases or Synthetases

\section{Activity and Role of Enzymes in metabolism}

Oxidoreductases: Oxidoreductases form a large group of enzymes concerned with biological oxidation and reduction i.e. the removal or addition of hydrogen atoms. They are again divisible into six main groups:

a. Oxidases: which use oxygen as hydrogen acceptor viz. tyrosine, cytochrome oxidase, uricase etc. 
b. Anaerobic dehydrogenases: which use some other substances as hydrogen acceptor viz. Malic, Succinic and Lactic dehydrogenase.

c. Hydro peroxidases: They use hydrogen peroxides as hydrogen acceptor viz. Peroxidases, Catalases.

d. Dehydrogenases or Aerobic dehydrogenases: Dehydrogenases which can use either oxygen or another substance as hydrogen acceptor are termed as Aerobic dehydrogenases viz. D\& L-amino acid oxidases, Xanthine oxidases, Aldehyde oxidases.

e. Oxygenases: which act on single hydrogen donor with incorporation of oxygen viz. Tryptophan oxygenase.

f. Hydroxylases: which act on paired donors with incorporation of oxygen into one donor viz. Phenylalanine 4 hydroxylase, Steroid hydroxylases.

Several oxidoreductases have co-enzymes for proper functioning. These hydrogen acceptors or co-enzymes are:

i. Pyridine compounds: These include NAD and NADP, in which nicotinamide part accepts hydrogen viz. the enzyme 'alcohol dehydrogenase' dehydrogenates or oxidises ethyl alcohol to acetaldehyde, provided the co-enzyme NAD is present.

ii. Riboflavin compounds: These are also known as flavoproteins because they contain as prosthetic group either Flavin mononucleotide (FMN) or Flavin adenine dinucleotide (FAD). The flavins can accept only one electron at a time. During Kreb's cycle, FAD accepts hydrogen from succinic acid.

iii. Iron porphyrin compounds or Cytochromes: These are iron containing proteins and work as electron carriers. The iron porphyrin part is referred to as a prosthetic group. The three cytochromes a, b, and c are respiratory enzymes involved in oxidation reduction reactions in a cell. The cytochromes are essential for the activity of specific apoenzymes.

iv. Cuproproteins: The cuproproteins are copper containing compounds, in which copper ions can exist in two oxidation states and it is believed that in cuproproteins, they undergo alternate oxidation and reduction. Here molecular oxygen acts as electron acceptor.

\section{Transferases}

This is a group of enzymes that catalyse the transfer of some group or radical, ' $R$ ', from one molecule $A$ to another molecule $B$. Thus, $A R+B=A+B R$. They are especially important for biological synthesis. Transaminases, transphosphorylases, transglycosidases and transacetylase are typical enzymes of this group. Creatine phosphoryl transferase, an important enzyme in muscles, catalyses the transfer of the 'energy rich' phosphate group from creatine phosphate to ADP to form ATP. The kinases mediate the transfer of a phosphate group specifically from ATP to particular substrate. The later are thus converted to the corresponding phosphate esters, whereas, ATP is reduced to ADP. viz. the metabolism of glucose involves first it's phosphorylation in the presence of enzyme Hexokinase, in which the phosphate group of ATPs is transferred to glucose.

\section{Hydrolases}

They catalyse the hydrolytic fission of substrate by direct addition of the elements of water across the bond which is split. The group includes the extracellular digestive enzymes and many intracellular enzymes viz. polysaccharides (amylases), glycosidases, esterases, peptidases (pepsin, chymotrypsin, trypsin), Amidases and hydrolytic deaminases (guanine deaminase).In the transmission of nerve impulses, the enzyme, acetylcholinesterase catalyses the breakdown of acetylcholine to choline and acetic acid.

\section{Lyases}

These are a group of enzymes that reversibly catalyse the removal of chemical groups from substrates non hydrolytically. Those which add or remove water are sometimes called as Hydrolases viz. aconitase, fumarase, enolase. Non - oxidative decarboxylases remove $\mathrm{CO}_{2}$ viz. Amino acid decarboxylase, carboxylase, carbonic anhydrase, aldolase (ketose 1 - phosphate aldolase) is included in this group because it catalyses the reversible addition of two molecules of triose phosphate to form fructose di-phosphate [1-3].

\section{Isomerases}

These are the enzymes that catalyse the interconversion of a compound to one of its isomers viz. in the anaerobic breakdown of carbohydrates to lactic acid, triose phosphate isomerase converts 3-phosphoglyceraldehyde to dihydroxy acetone phosphate.

\section{Ligases or Synthetases:}

These are the enzymes that catalyse the linking together of two molecules, coupled with the breaking of a pyrophosphate bond of ATP viz. glutamine synthetase, Acetyl co-enzyme-A synthetase $[4,5]$.

\section{General Properties of Enzymes}

a) An enzyme is a protein that is synthesized in a living cell and catalyses or speeds up a reaction.

b) The enzymes work at extremely low concentrations.

c) An enzyme being a protein, loses its catalytic properties, if subjected to agents like heat, strong acids and bases, organic solvents or other materials which denature the protein.

d) The efficiency with which an enzyme accelerates a reaction can be illustrated by its turn over number (the number of moles of substrate acted on by 1 mole of enzyme per unit time). One mole of enzyme can convert from 10,000 to one million moles of substrate per minute. 
e) Because of their colloidal nature, enzymes undergo 'aging' and destruction, therefore, they must be constantly replenished by further synthesis in the body.

f) The enzymes are highly specific i.e. each enzyme usually acts on a single substrate or a group of closely related substrates.

On the basis of above discussion, it is clear that a particular enzyme is effective in accelerating a reaction in either direction, for it does not determine the direction of a reaction. Thus, most enzymatic reactions are reversible and are of great help in metabolism.

\section{ISSN: 2574-1241}

DOI: $10.26717 /$ BJSTR.2020.24.004090

Neerja Kapoor. Biomed J Sci \& Tech Res

(C) (P) This work is licensed under Creative

Submission Link: https://biomedres.us/submit-manuscript.php

\section{References}

1. Maritim AC (2003) Metabolic Enzymes. J Biochem Mol Toxicol 17(1): 24-38.

2. Hsu PP et al. (2008) Metabolic Enzymes. Cell 134(5): 703-707.

3. Schulenburg C, Brian G Millar (2014) Enzyme Recruitment and its Role in Metabolic Expansion. Biochemistry 53(5): 836-845.

4. Jack Ori (2017) What is the role of enzymes in metabolism? Sciencing.

5. Almonacid DE, Babbitt PC (2011) Toward mechanistic classification of enzyme functions. Currn Opin Chem Biol 15: 435-442.

$\begin{array}{ll}\text { BIOMEDICAL } & \text { Assets of Publishing with us } \\ \text { RESEARCHES } & \text { - Global archiving of articles } \\ \text { - Immediate, unrestricted online access }\end{array}$

